\title{
Thermal stability and combustibility of rubbers and sealing plates
}

\author{
L. Ślusarski · G. Janowska $\cdot$ P. Schulz
}

Received: 3 February 2012/ Accepted: 25 April 2012/Published online: 4 June 2012

(C) The Author(s) 2012. This article is published with open access at Springerlink.com

\begin{abstract}
The present paper describes the test results concerning the thermal properties and flammability of the selected sealing plates and rubbers that may become components of plates. The thermal analysis methods (DTA, DSC, TG, and DTG) and flammability methods (OI, rate of burning in air, and ignition temperature) were used in this study. The thermal analysis of plates was also performed under isothermal conditions. It was stated that investigated sealing plates belong to the group of flame-retardant materials and type of rubber included in plate influences its thermal stability and combustibility.
\end{abstract}

Keywords Combustibility - Thermal analysis .

Thermal properties $\cdot$ Rubbers $\cdot$ Sealing plates

\section{Introduction}

Sealing plates have been manufactured by the calendering method almost since the beginning of the last century and they still find a wide application in technology, and their replacement with other types of material is rather not likely although some attempts are undertaken in that direction [1-3]. In the market, one can observe new types of sealing plates adapted to users' growing requirements, but information on their composition and manufacturing processes is rather scant. In the case of plates made by European

L. Ślusarski · G. Janowska ( $\square)$

Faculty of Chemistry, Institute of Polymers and Dye Technology, Technical University of Łódź, Lodz, Poland e-mail: grazyna.janowska@p.lodz.pl

P. Schulz

Gambit Lubawka, Lubawka, Poland companies, their producers display information that the plates contain no asbestos.

Sealing plates constitute a particular type of composite materials. However, in the case of conventional structural composites, a polymer constitutes the continuous phase (matrix), in which the remaining components are dispersed (so-called reinforcement). The polymer content in such composites ranges from 50 to $60 \%$ by wt. The relationship between the structure, morphology, and properties of polymeric composites has been systematically investigated and the results obtained are used to improve the technology of their manufacture. Undoubtedly, such investigations are also carried out in the case of sealing plates, but their results are not published. There is a clear difference between the compositions of both the types of composites. In sealing plates, the content of rubber ranges from 10 to $20 \%$ by wt. Thus, it does not fulfill the role of continuous phase but a sort of binder. Therefore, the test results of typical polymeric composites cannot be used in the technology of sealing plates more so that different requirements are imposed on both types of materials. Depending on application, both general and specific requirements are imposed on sealing plates. The first category includes tribological properties, compressibility, elastic recovery, gas permeability (depending on gas type, pressure and temperature), and resistance to gases and/or liquids stored in a given container or transported in a pipeline. The specific properties required include, first of all, thermal stability and flammability. The manufacturers of sealing plates usually inform about a permissible temperature of their use with no explanation about how it was determined. This is a very important parameter especially in the case of using gaskets cut out from the plates in steam or gas pipelines and combustion engines. Usually, considerably less attention is paid to the flammability of sealing plates and gasket cut out 
from them although it is of great importance, e.g., when gaskets can be exposed to fire.

This paper presents test results concerning the thermal properties and flammability of rubbers that may become components of sealing plates. The aim of the study was to assess the effect of components included in sealing plates, especially macromolecular ones, on their thermal stability and resistance to the action of fire.

\section{Experimental}

The materials for study included 4 rubbers: acrylic Hy Temp. rubber (AR-71), from ZEON CHEMICALS; butadiene-acrylonitrile rubbers from BAYER; NBR: Perbunan NT 1845 (NT-1845) and Perbunan NT 3945 (NT-3945); and hydrogenated NBR rubber: HNBRTherbunan A-4307 from BAYER (A-4307); 3 types of sealing plates designated as Gambit AF-400 (AF-400), Universal AF-200 (AF-200), and Gambit SOFT (SOFT) from Gambit Lubawka.

The thermal analysis of rubbers and sealing plates was carried out under air by means of a derivatograph from MOM Budapest, within the temperature range: $\Delta T=$ $20 \div 800{ }^{\circ} \mathrm{C}$, using platinum crucible, weighed portions of $90 \mathrm{mg}$, and heating rate $7.9^{\circ} \mathrm{C} \mathrm{min}^{-1}$. The thermal analysis of sealing plates under air was also performed using a thermo-balance TG-209 from Netzsch under isothermal
Fig. 1 Thermal curves (DTA, TG, and DTG) of rubbers (air atmosphere, platinum crucible, weight portions of $90 \mathrm{mg}$, and heating rate $7.9^{\circ} \mathrm{C} \min ^{-1}$ )
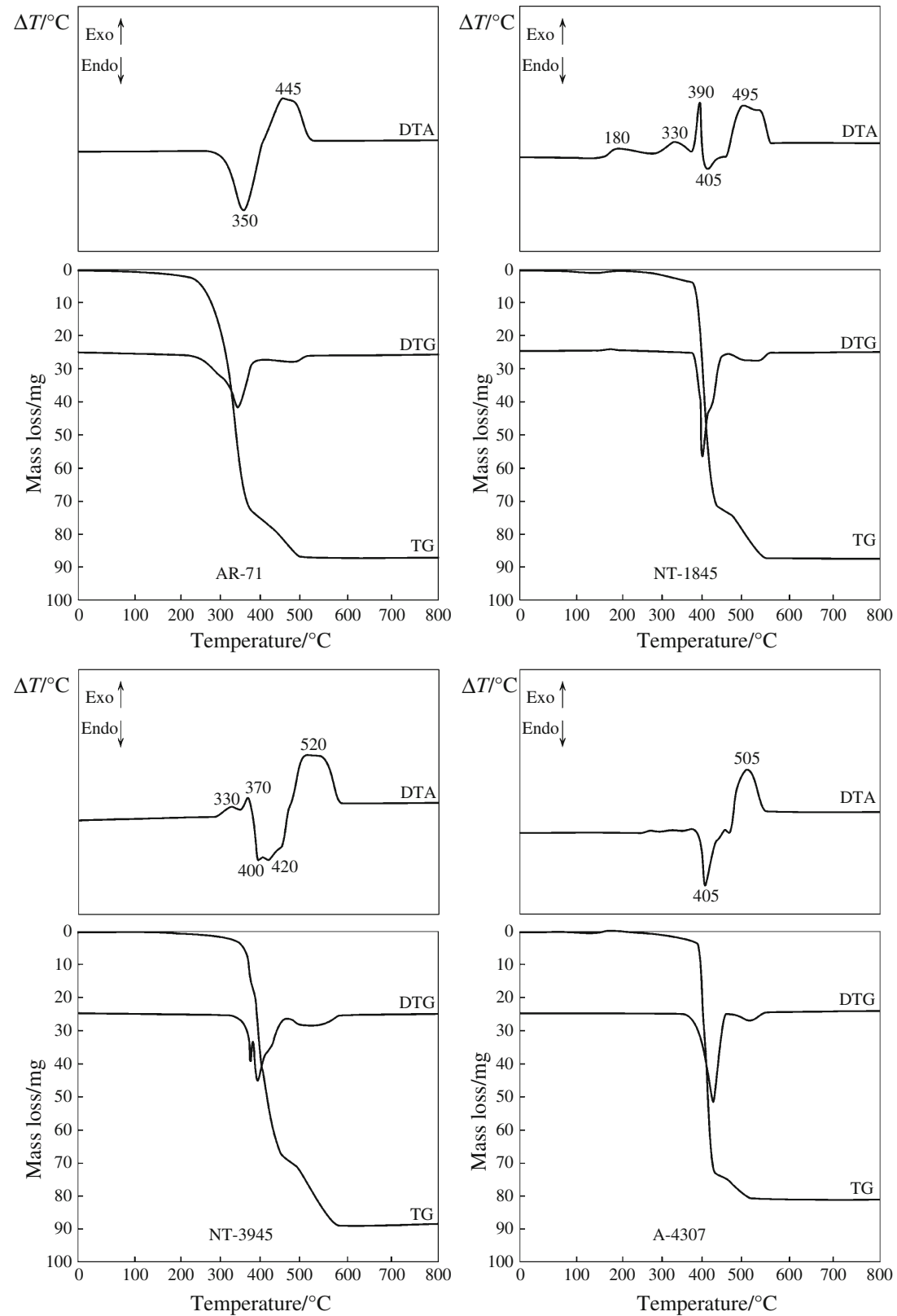
conditions, using aluminum crucible, weighed portions of about $9 \mathrm{mg}$ each and heating rate of $10{ }^{\circ} \mathrm{C} \mathrm{min}^{-1}$. In the case of isothermal conditions, plate samples were heated at a rate of $10{ }^{\circ} \mathrm{C} \mathrm{min}^{-1}$ up to $T=150,200$ or $300{ }^{\circ} \mathrm{C}$, followed by annealing at these temperatures for $2 \mathrm{~h}$.

The thermal analysis of rubbers and plates was also carried out under neutral gas using a DSC-204 micro-calorimeter from Netzsch within the temperature range of $-100 \div 500{ }^{\circ} \mathrm{C}$, using weighed portions, and heating rate as mentioned above.

The flammability of sealing plates was determined by the method of oxygen index (OI), using an apparatus of our own construction and to measure combustion time in air $(t)$. Sample dimensions, their positions, and treatment with flame in both cases of determination were the same. Test samples with dimensions of $100 \times 10 \times 2 \mathrm{~mm}$ were cut out from sealing plates by means of a special punching die. Samples were ignited for $15 \mathrm{~s}$ with a gas burner supplied with a propane-butane mixture.

During flammability tests, the effect of the duration of flame action on a plate sample on the time of its selfextinguishing and on the sample mass loss due to combustion was also examined. Samples were ignited for 5, 15, 30,60 , and $120 \mathrm{~s}$ with the flame of a gas burner as above.

The ignition temperature $(\mathrm{Tz})$ of rubbers and sealing plates, defined as the lowest temperature at which the sample of polymer or polymeric material heated in a precisely specified way, emits a quantity of gaseous thermal decomposition products sufficient for the formation of a mixture with air that ignites when flame approaches, was determined using a tester from ANKO according to PN-69/ C-89022.

\section{Results and discussion}

From among all the rubbers tested, acrylic rubber (AR-71) is characterized by the lowest thermal stability determined by both $T_{5}$ and $T_{50}$ coefficients as well as by the lowest thermal decomposition rate, $\mathrm{d} m / \mathrm{d} t$ (Fig. 1; Table 1). The thermal decomposition of this elastomer as shown by the great endothermic change recorded in the DTA curve, $T_{\text {Rmax }}=350{ }^{\circ} \mathrm{C}$, begins at $T=205^{\circ} \mathrm{C}$ (Fig. 1).

The character of thermal processes of polymers at elevated temperature influences their thermal stability [5-7]. The high, comparable thermal stability of the remaining rubbers, determined with coefficients $T_{5}$ and $T_{50}$, results from the fact that due to heating within the range of $160-360{ }^{\circ} \mathrm{C}$ they are thermally cross-linked (Fig. 1). The yield of these processes increases with increasing number of butadiene units in the macromolecules of polymers $[4,7,8]$. In this connection, butadiene-acrylonitrile rubber (NT-1845) shows a higher thermal stability, determined especially at coefficient $T_{5}$, compared to that of NT -3945 . However, it should be clearly underlined that the higher content of acrylonitrile mers in macromolecules favors the cyclization of neighboring cyano groups during the thermal decomposition of the copolymer, which considerably decreases the rate of this process and consequently reduces the flammability of the macromolecular compound (Table 1).

The processes of thermal cross-linking proceed to a minimal extent during heating of hydrogenated butadieneacrylonitrile rubber (A-4307), which results from the residual content of butadiene mers. This rubber is characterized by the highest temperature of decomposition under thermo-oxidative conditions, $T_{\mathrm{R}}$, and the highest temperature of the maximal rate of this process, $T_{\mathrm{Rmax}}$, among the elastomers are investigated (Table 1).

The sealing plates tested are characterized by different thermal stabilities. A considerably lower thermal stability of plate SOFT, determined with $T_{5}$, compared to that of $\mathrm{AF}-400$ or AF-200 is due to the evaporation of water (3.3\%) adsorbed on cellulose fibers included in this plate (Figs 2, 4). Plate SOFT also shows the lowest temperature of the maximal rate of thermal decomposition, $T_{\mathrm{Rmax}}$, that proceeds almost twice as fast as that of AF-400 or AF-200. Plates AF-400 and AF-200 are also characterized by a

Table 1 The results of thermal analysis of rubbers and sealing plates

\begin{tabular}{lllllll}
\hline Rubber or plate symbol & $T_{5} /{ }^{\circ} \mathrm{C}$ & $T_{50} /{ }^{\circ} \mathrm{C}$ & $T_{\mathrm{R}} /{ }^{\circ} \mathrm{C}$ & $T_{\mathrm{Rmax}} /{ }^{\circ} \mathrm{C}$ & $\mathrm{d} m / \mathrm{d} t / \mathrm{mm}$ & $P / \%$ \\
\hline AR-71 & 245 & 330 & 205 & 350 & 33 & 17.77 \\
NT-1845 & 375 & 410 & 250 & 395 & 66 & 18.88 \\
NT-3945 & 345 & 400 & 255 & 395 & 39 & 22.22 \\
A-4307 & 360 & 410 & 300 & 420 & 55 & 0 \\
AF-400 & 360 & - & 250 & 525 & 6 & 1.66 \\
AF-200 & 355 & - & 170 & 510 & 5 & 73.88 \\
SOFT & 225 & - & 200 & 290 & 11 & 73.34 \\
\hline
\end{tabular}

$T_{5}$ temperature of $5 \%$ sample mass loss, $T_{50}$ temperature of $50 \%$ sample mass loss, $T_{\mathrm{R}}$ initial temperature of sample thermal decomposition, $T_{\mathrm{R} \max }$ temperature of sample thermal decomposition maximum rate, $\mathrm{d} m / \mathrm{d} t$ maximum rate of sample thermal decomposition, $P$ residue after sample decomposition, $P_{800}$ residue after sample heating up to $T=800{ }^{\circ} \mathrm{C}$ 
Fig. 2 Thermal curves (DTA,

TG, and DTG) of sealing plates (air atmosphere, platinum crucible, weight portions of $90 \mathrm{mg}$, and heating rate $7.9^{\circ} \mathrm{C} \min ^{-1}$ )
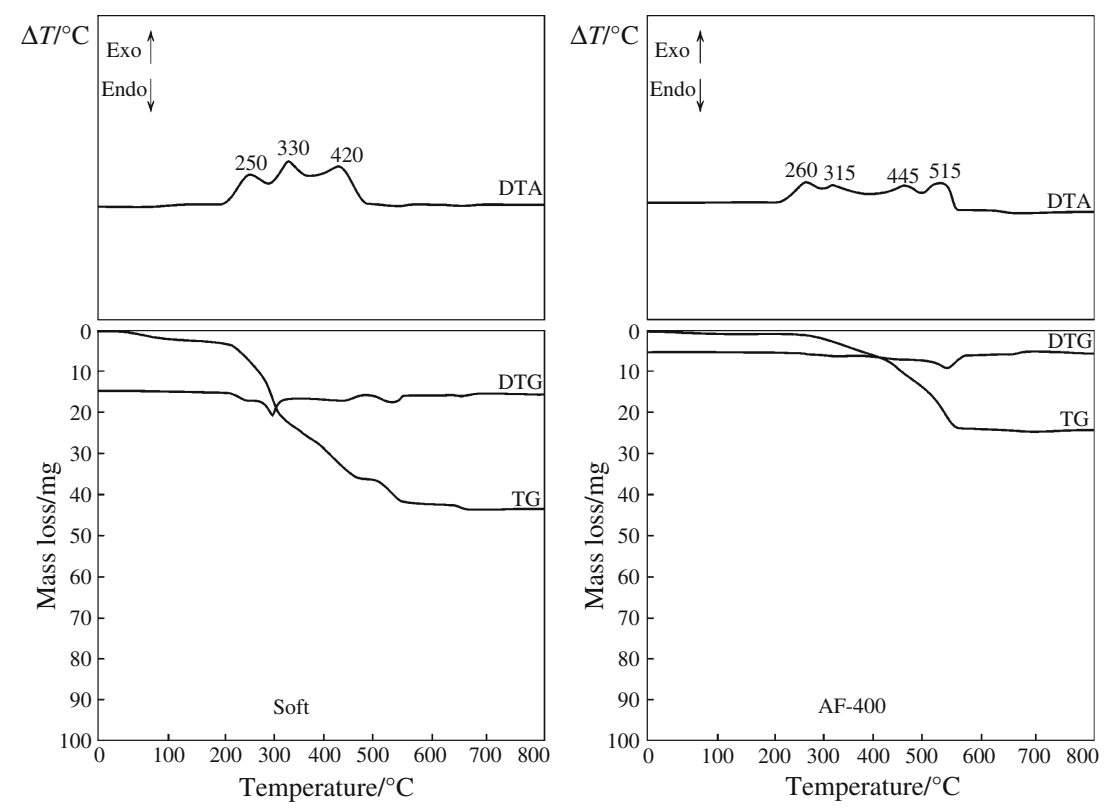

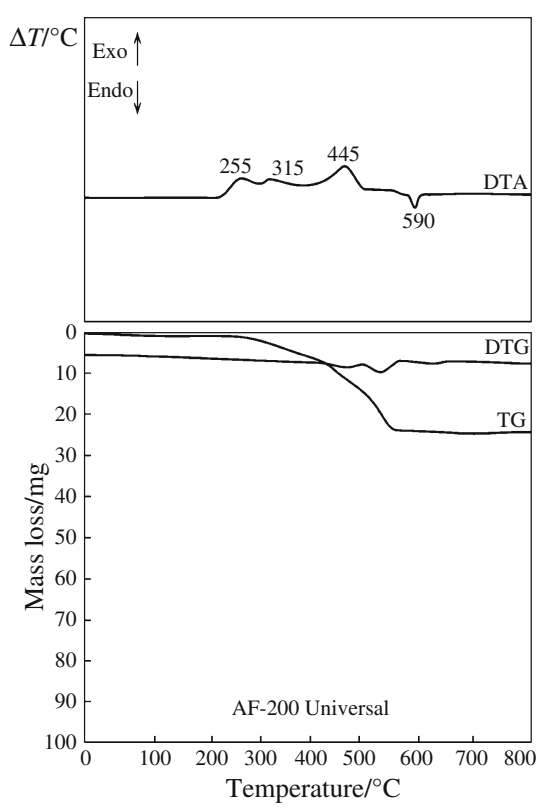

higher residue determined with coefficients $P$ and $P_{800}$ compared with that of plate SOFT (Table 1).

The transition of the rubbers investigated from the glassy to elastic state, $T_{\mathrm{g}}$, occurs within the range of negative temperatures (Table 2, Fig. 3).

Acrylic rubber AR-71 shows the highest glass transition temperature. Further heating of this elastomer, after its transition into elastic state at $T_{\mathrm{g}}=-8{ }^{\circ} \mathrm{C}$, causes polymer decomposition beginning at a temperature of $272{ }^{\circ} \mathrm{C}$. The destruction of the rubber is revealed by the high endothermic peak recorded in the DSC curve at $T=393{ }^{\circ} \mathrm{C}$ (Fig. 3).

The considerably different glass transition temperatures of butadiene-acrylonitrile rubbers: NT-1845 and NT3945 , are caused by the different content of acrylonitrile
Table 2 Glass temperature $\left(T_{\mathrm{g}}\right)$ of investigated rubbers and rubbers included in sealing plates

\begin{tabular}{llllllll}
\hline $\begin{array}{l}\text { Rubber } \\
\text { or plate }\end{array}$ & AR- & NT- & NT- & A- & AF- & AF- & SOFT \\
symbol & 1845 & 3945 & 4307 & 400 & 200 & \\
\hline$T_{\mathrm{g}}{ }^{\circ} \mathrm{C}$ & -8 & -41 & -15 & -12 & $-41,-11$ & -12 & -21 \\
\hline
\end{tabular}

combined with them affecting the segmental mobility of elastomeric chains (Table 2; Fig. 3). The content of acrylonitrile also affects the yield of the thermal cross-linking of these elastomers within the temperature range of $\Delta T=$ 260-423 and $\Delta T=260-412{ }^{\circ} \mathrm{C}$ (Fig. 3). The decomposition 


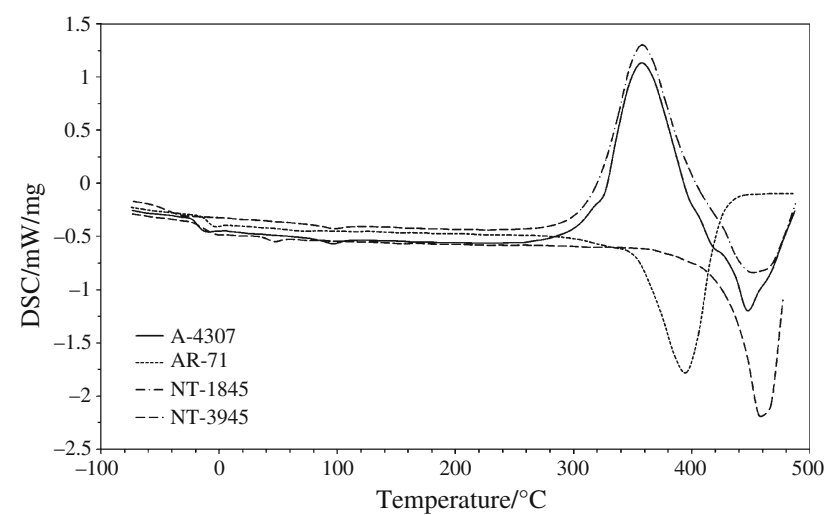

Fig. 3 DSC curves of rubbers (nitrogen atmosphere, aluminum crucible, weight portions $\sim 9 \mathrm{mg}$, and heating rate $10{ }^{\circ} \mathrm{C} \mathrm{min}^{-1}$ )

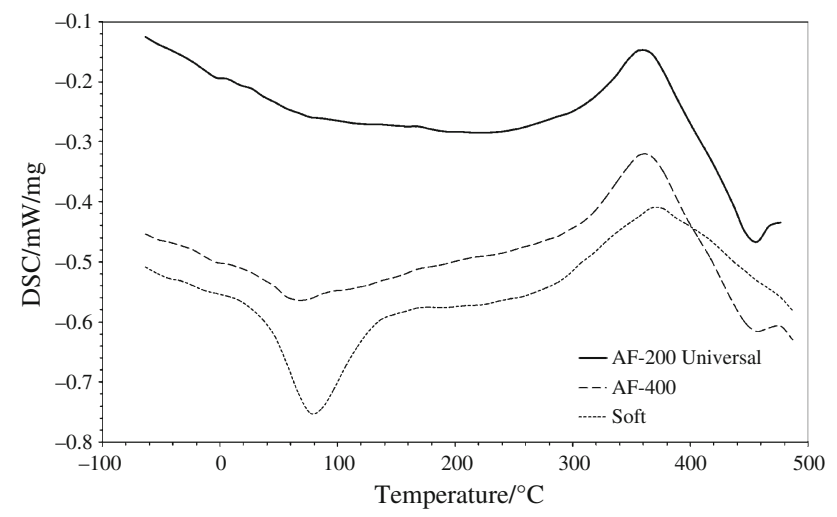

Fig. 4 DSC curves of sealing plates (nitrogen atmosphere, aluminum crucible, weight portions $\sim 9 \mathrm{mg}$, and heating rate $10^{\circ} \mathrm{C} / \mathrm{min}$ )

of thermally cross-linked rubbers occurs at $\Delta T=423-479$ and $\Delta T=412-474{ }^{\circ} \mathrm{C}$, while the temperature of the maximal destruction rate is $T=443$ and $T=448{ }^{\circ} \mathrm{C}$ (Fig. 3).

Hydrogenated butadiene-acrylonitrile rubber A-4307 heated at $\Delta T=-100 \div 500{ }^{\circ} \mathrm{C}$ undergoes glass transition at $T_{\mathrm{g}}=-12{ }^{\circ} \mathrm{C}$ and thermal decomposition beginning at $T=360{ }^{\circ} \mathrm{C}$ (Fig. 3).

From the analysis of the DSC curve of AF-400 plate, it follows that two polymers are included in it (Fig. 4). These show glass transition temperatures at -41 and $-11^{\circ} \mathrm{C}$, respectively. The first $T_{\mathrm{g}}$ indicates that $\mathrm{AF}-400$ plate contains nitrile rubber, e.g., NT-3945. The presence of this elastomer is also confirmed by the exothermic process recorded at $T=360{ }^{\circ} \mathrm{C}$ connected with its thermal crosslinking. An intensive thermal destruction of the plate components, first of all macromolecular ones, occurs over $400{ }^{\circ} \mathrm{C}$.

The glass transition of the rubber included in AF-200 plate occurs at $T_{\mathrm{g}}=-12{ }^{\circ} \mathrm{C}$ (Table 2; Fig. 4). This rubber is thermally cross-linked at $T=235{ }^{\circ} \mathrm{C}$ and destructed at $T=400{ }^{\circ} \mathrm{C}$.
The glass transition temperature of the polymer included in SOFT plate is $T_{\mathrm{g}}=-21^{\circ} \mathrm{C}$ (Fig. 4; Table 2). From both, its DTA and DSC curves it follows that SOFT plate contains water adsorbed on cellulose fiber present in its composition (Figs. 1, 4). The evaporation of the water adsorbed is the endothermic process recorded in DSC curve at $T=79^{\circ} \mathrm{C}$. The great exothermic transition at $T=371{ }^{\circ} \mathrm{C}$ indicates the thermal cross-linking of the rubber contained in it, the intensive thermal decomposition of which in oxygenless atmosphere begins at $T=480{ }^{\circ} \mathrm{C}$ (Fig. 4).

The results of thermal analysis show that the mass losses of the plate samples tested heated for $2 \mathrm{~h}$ at $T=150,200$, or $300{ }^{\circ} \mathrm{C}$ are different being clearly connected with their thermal stability (Tables 1, 3). The lowest mass losses occur during heating $\mathrm{AF}-400$ plate that is characterized by the highest values of thermal stability parameters designated as $T_{5}, T_{50}, T_{\mathrm{R}}, T_{\mathrm{Rmax}}, P$, and $P_{800}$ (Table 1).

The lowest mass loss of AF-400 plate occurring during its heating at $T=300{ }^{\circ} \mathrm{C}$ is due to the relatively high yield of the cross-linking processes of the elastomer included in it occurring at the heating temperature (Fig. 4).

From among all the elastomers tested, nitrile rubbers show the lowest ignition temperature, $T_{\mathrm{z}}$ (Table 4). The highest $T_{\mathrm{z}}$ of A-4307 rubber, above $400{ }^{\circ} \mathrm{C}$, results from its high thermal stability expressed by both $T_{5}$ and $T_{50}$ coefficients and the temperature of thermal decomposition start $T_{\mathrm{R}}$ (Tables 1, 4). Despite the lowest thermal stability parameters of acrylic rubber AR-71 from among the polymers tested, it shows a high ignition temperature (Tables 1,4). The thermal decomposition products of this polymer, after mixing with air, ignite after its heating to $T=365{ }^{\circ} \mathrm{C}$. This results, first of all, from the low thermal decomposition rate of this rubber $(\mathrm{d} m / \mathrm{d} t$, Table 1$)$. It

Table 3 Mass losses of sealing plates caused by their heating under isothermal conditions

\begin{tabular}{lllr}
\hline Plate symbol $/ \%$ & AF-400 & AF-200 & SOFT \\
\hline$\Delta m_{150}$ & 1.30 & 3.10 & 4.00 \\
$\Delta m_{200}$ & 2.40 & 1.65 & 3.45 \\
$\Delta m_{300}$ & 2.60 & 3.50 & 18.00 \\
\hline
\end{tabular}

$\Delta m_{150}$ mass loss of the sample caused by its heating for $2 \mathrm{~h}$ at $T=150{ }^{\circ} \mathrm{C}, \Delta m_{200}$ mass loss of the sample caused by its heating for $2 \mathrm{~h}$ at $T=200{ }^{\circ} \mathrm{C}, \Delta m_{300}$ mass loss of the sample caused by its heating for $2 \mathrm{~h}$ at $T=300{ }^{\circ} \mathrm{C}$

Table 4 Ignition temperature $\left(T_{\mathrm{z}}\right)$ of investigated rubbers and sealing plates

\begin{tabular}{llllllll}
\hline $\begin{array}{l}\text { Rubber or } \\
\text { plate symbol }\end{array}$ & $\begin{array}{l}\text { AR- } \\
71\end{array}$ & $\begin{array}{l}\text { NT- } \\
1845\end{array}$ & $\begin{array}{l}\text { NT- } \\
3945\end{array}$ & $\begin{array}{l}\text { A- } \\
4307\end{array}$ & $\begin{array}{l}\text { AF- } \\
400\end{array}$ & $\begin{array}{l}\text { AF- } \\
200\end{array}$ & SOFT \\
\hline$T_{\mathrm{Z}} /{ }^{\circ} \mathrm{C}$ & 365 & 344 & 346 & $>400$ & $>400$ & $>400$ & 332 \\
\hline
\end{tabular}


should also be expected that water vapor is included in the products of acrylic rubber destruction.

The diversified thermal stability of the plates tested affects their ignition temperature (Tables 1, 4). The destruction products of both AF-400 and AF-200 plates heated to $T=400{ }^{\circ} \mathrm{C}$ do not ignite under the influence of the gas burner flame.

The low thermal stability of SOFT plate determined by the value of $T_{5}$, but in the first place by the temperature of the maximal thermal decomposition rate, $T_{\mathrm{Rmax}}$, is the cause of its lowest ignition temperature, $T_{Z}$ (Tables 1,4 ). The low ignition temperature of SOFT plate also results from the high rate of its thermal decomposition, $\mathrm{d} m / \mathrm{d} t$ (Table 1 ).

The type of rotameters in the oxygen index tester used allows the highest oxygen concentration in the oxygennitrogen mixture to be $240 \mathrm{l} / \mathrm{h}$ (Table 5). At this oxygen content, one cannot precisely determine the value of OI of the sealing plates under investigation. From the measurements performed results that values of OI of the investigated sealing plates are higher than 0.375 (OI > 0.375). Thus these plates are flame-retardant materials.

Both under the conditions of OI test and measurement in air, the samples of sealing plates ignited under the influence of the external fire source. Under the conditions of OI test, the combustion process occurred on the sample peripheries followed by their self-extinguishing as soon as the gas

Table 5 Flammability of sealing plates under the conditions of oxygen index tests (nitrogen content in the oxygen-nitrogen mixture amounts to $400 \mathrm{~L} \mathrm{~h}^{-1}$ )

\begin{tabular}{llll}
\hline $\begin{array}{l}\text { Symbol } \\
\text { of plate }\end{array}$ & $\begin{array}{l}\text { Time of } \\
\text { action of the } \\
\text { burner } \\
\text { flame/s }\end{array}$ & $\begin{array}{l}\text { Time, after which the } \\
\text { sample tested } \\
\text { extinguishes as soon as } \\
\text { the source of fire is } \\
\text { removed/s }\end{array}$ & $\begin{array}{l}\text { Mass loss of the } \\
\text { sample caused } \\
\text { by its burning/\% }\end{array}$ \\
\end{tabular}

\begin{tabular}{lrrr}
\hline AF-400 & 5 & 87 & 22.70 \\
& 15 & 95 & 22.70 \\
& 30 & 91 & 22.47 \\
& 60 & 94 & 22.85 \\
& 120 & 92 & 22.84 \\
AF-200 & 5 & 19 & 1.54 \\
& 15 & 14 & 2.31 \\
& 30 & 15 & 4.31 \\
& 60 & $50 a$ & 5.94 \\
& 120 & $60 a$ & 7.58 \\
SOFT & 5 & 83 & 35.56 \\
& 15 & 82 & 33.36 \\
& 30 & 67 & 35.58 \\
& 60 & 38 & 36.69 \\
& 120 & $80 a$ & 34.55
\end{tabular}

$a$ time, after which the flame of the whole burning sample on its peripheries disappeared during of source action, appeared glow that disappeared as soon as the gas burnet was removed burner was removed. During a long treatment of AF-200 or SOFT plate samples with flame (60 or $120 \mathrm{~s})$, the flame remains for the period of time given in Table 5 passing then into glow as soon as the gas burner was removed.

From the comparative analysis of the measurement results given in Table 5, it follows that AF-200 plate is characterized by the highest resistance to the action of flame, determined by both the time, after which the sample is extinguished as soon as the gas burner is removed, and the mass loss due to its combustion. This plate, under the influence of flame acting for 60 or $120 \mathrm{~s}$, undergoes combustion on its peripheries for $50 \mathrm{~s}$ followed by glow that disappears as soon as the gas burner is removed.

The sealing plates tested underwent self-extinguishing in air after a considerably shorter time than under the conditions of OI tests and the mass losses of the samples due to their combustion were also considerably lower (Tables 5, 6). The course of the combustion processes of plate samples in air considerably differed from their combustion under the conditions of OI test. During the combustion in air, under the influence of the fire source, the sample ignited and the flame comprised the peripheries of its upper part, which disappeared as soon as the gas burned was removed within the time not exceeding $3 \mathrm{~s}$ (Table 6). During a long time of the fire source action (60 or $120 \mathrm{~s}$ ) on the samples of AF-200 or SOFT plates, the flame remained

Table 6 Flammability of sealing plates in air

\begin{tabular}{lrll}
\hline $\begin{array}{l}\text { Symbol } \\
\text { of plate }\end{array}$ & $\begin{array}{l}\text { Time of } \\
\text { action of the } \\
\text { burner } \\
\text { flame/s }\end{array}$ & $\begin{array}{l}\text { Time, after which the } \\
\text { sample tested } \\
\text { extinguishes as soon as } \\
\text { the source of fire is } \\
\text { removed/s }\end{array}$ & $\begin{array}{l}\text { Mass loss of the } \\
\text { sample caused } \\
\text { by its burning/\% }\end{array}$ \\
\hline AF-400 & 5 & 2.0 & 0.24 \\
& 15 & 2.0 & 0.63 \\
& 30 & 1.5 & 1.54 \\
& 60 & 2.5 & 2.36 \\
& 120 & 2.0 & 4.01 \\
AF-200 & 5 & 1.5 & 0.16 \\
& 15 & 3.0 & 0.37 \\
& 30 & 2.0 & 0.84 \\
& 60 & $23 a$ & 1.34 \\
& 120 & $26 a$ & 1.77 \\
SOFT & 5 & 1.0 & 0.20 \\
& 15 & 3.0 & 0.59 \\
& 30 & 2.0 & 1.35 \\
60 & $50 a$ & 2.13 \\
120 & $52 a$ & 2.96
\end{tabular}

$a$ under the influence of flame the sample ignites and its flame comprises the peripheries of its upper part. The flame remains for about $50 \mathrm{~s}$ and then changes into glow that disappears as soon as the gas burner is removed 
within the time given in Table 5 followed by glow that disappeared as soon as the gas burned was removed.

The measurement results of the plate flammability in air have shown that AF-200 plate is characterized by the highest resistance to the action of fire determined by both the time after which the sample extinguishes as soon as the gas burner is removed and the sample mass loss caused by its combustion (Table 6). It is not excluded that the highest resistance of AF-200 plate is due to the chalk included in it as indicated by a small endothermic process recorded in the DTA curve at $T=590{ }^{\circ} \mathrm{C}$ caused by a partial thermal decomposition of the filler (Fig. 2). This decomposition decreases the energetic balance of the burning sample, while the inflammable $\mathrm{CO}_{2}$ formed during this process reduces the yield of the free-radical oxidation processes proceeding in the flame and impedes the diffusion of oxygen to the combustion zone. This filler also adsorbs the decomposition products of the components, especially macromolecular ones, included in the plate; therefore, their lower quantities pass to the flame during combustion.

\section{Conclusions}

The type of rubber included in sealing plate influences its thermal stability and flammability. Values of thermal stability parameters of elastomers and elastomeric materials such as: $T_{5}, T_{50}, \mathrm{~d} m / \mathrm{d} t, \mathrm{Pw}$ and also kind of thermal destruction products influencing their combustibility, depend on chemical structure of macromolecules. Consequently, flammability of butadiene-acrylonitrile copolymers, known as nitrile rubbers, commonly used in sealing plates technology, depends on content of acrylonitrile monomer units.
The mass losses of the plate samples heated under isothermal conditions at $T=150,200$, or $300{ }^{\circ} \mathrm{C}$ are clearly connected with their thermal stability.

The sealing plates tested belong to the group of flameretardant materials. They undergo self-extinguishing after removing the source of fire both in air and under the conditions of OI test. The process of self-extinguishing in air occurs after a considerably shorter time and the weight losses of the samples caused by their combustion also are considerably smaller.

Acknowledgements This study was financed as a research-development project PR Nr N R15 0037 06/2009.

Open Access This article is distributed under the terms of the Creative Commons Attribution License which permits any use, distribution, and reproduction in any medium, provided the original author(s) and the source are credited.

\section{References}

1. Curie R. Materials usage in static sealing applications. Seal Technol. 2002;11:6-10.

2. Flitney B. Review of features in sealing technology during the last year. Seal Technol. 2005;5:6-11.

3. Fitney B. Sealing today. Seal Technol. 2006;8:6-10.

4. Janowska G, Rybiński P. Właściwości termiczne kauczuków butadienowo-akrylonitrylowych. Polimery. 2003;48:183-7.

5. Turi EA. Thermal characterization of polymeric materials. San Diego: Academic Press; 1997.

6. Pielichowski K, Njuguna J. Thermal degradation of polymeric materials. Shawbury: Rapra; 2005.

7. Rybiński P, Janowska G. Analiza termiczna i palność kauczuków butadienowo-akrylonitrylowych. Przem Chem. 2003;8-9:908-10.

8. Janowska G, Rybiński P, Helwig M, Dąbrowski W, Majewski K. Flammability of butadiene-acrylonitrile rubbers. J Thermal Anal Calorim. 2004;75:249-56. 